\title{
Promethazine Inadvertently Instilled into the Eye Causes Prolonged Mydriasis
}

\author{
Anan H Abbasi* \\ Department of Ophthalmology, Bar-Ilan University, Israel
}

Submission: February 02, 2017; Published: March 30, 2017

*Corresponding author: Anan H Abbasi, MD, MSc, Department of Ophthalmology, Ziv Medical Center, Safed, Israel, Tel:+972502288800; Fax:+97246828444; E-mail: abbasi100@gmail.com

\section{Abstract}

Promethazine is a phenothiazine derivative with potent antihistaminic properties. It is usually used for the treatment of allergic conditions, often given at night because of its marked sedative effects. It is usually given orally but can be given by deep intramuscular injection or slow intravenous injection in emergencies [1]. Promethazine overdose might cause anticholinergic manifestations such as dry mouth, mydriasis and blurred vision.

In this case report, inadvertently instilled into the eye, Promethazine caused prolonged mydriasis (up to 24 hours). Direct ocular effect of Promethazine has not been reported previously in the literature. This is to remind and reinforce the anticholinergic effects of Promethazine that might be long lasting and should be taken into consideration when prescribing this medication, knowing that in many countries Promethazine is available as an over-the-counter (OTC) medication either alone as a tablet or liquid preparation or in combination with paracetamol and codeine phosphate as a syrup.

Keywords: Promethazine; Phenergan; Mydriasis; Antihistaminic; Anticholinergic

\section{Case Report}

Promethazine is a phenothiazine derivative with potent antihistaminic properties. It is usually used for the treatment of allergic conditions, often given at night because of its marked sedative effects. It is usually given orally but can be given by deep intramuscular injection or slow intravenous injection in emergencies. Promethazine overdose might cause anticholinergic manifestations such as dry mouth, mydriasis and blurred vision.

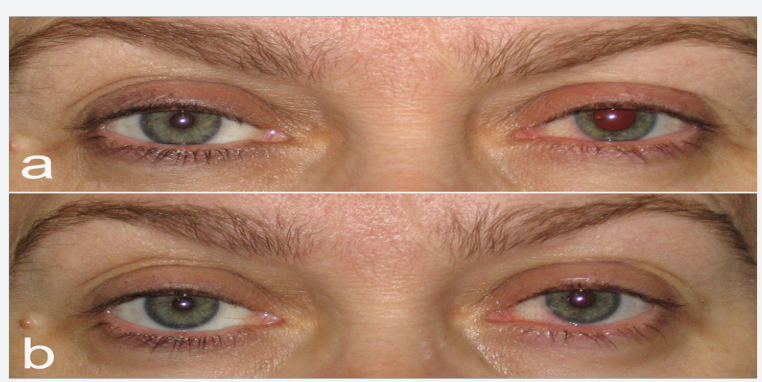

Figure 1a \& 1b: Examination of left eye revealed a fixed dilated pupil and nasal conjunctival irritation without any visible rupture of the sphincter muscle. b. Examination of the left eye the day after (15 hours later) revealed still an unequal but responsive pupils, with almost full resolution of the nasal conjunctival irritation.
I report a case of an otherwise healthy female who presented to the ophthalmic emergency room with unilateral mydriasis due to promethazine which was inadvertently instilled into her left eye. The 49-year-old nurse presented with irritation and pain in her left eye which started after one of the patients suffering from dementia spitted the promethazine tablet she gave her few seconds earlier directly to her left eye. On examination best-corrected visual acuity was $6 / 7$ in both eyes. Examination of left eye revealed a fixed dilated pupil and nasal conjunctival irritation without any visible rupture of the sphincter muscle (Figure 1a). Moving the lower lid anteriorly revealed small remnants of the tablet that were removed. Intraocular pressures and fundal examination were unremarkable. Moreover, her blood pressure rose to $160 / 90$ and therefore she was kept for observation until hemodynamically stabilized. Eventually, she was discharged with topical medications to relief her symptoms and was asked to come for a follow up examination the other day. It is worth mentioning that on her examination four hours after the event and before leaving the emergency room her left pupil was still dilated and unresponsive to light. Examination of the left eye the day after (15 hours later) revealed still an unequal but responsive pupils, with almost full resolution of the nasal 
conjunctival irritation (Figure 1b). After a 2-day follow-up the pupil returned to normal size.

To conclude, when inadvertently instilled into the eye, Promethazine caused prolonged mydriasis (up to 24 hours). Direct ocular effect of Promethazine has not been reported previously in the literature. This is to remind and reinforce the anticholinergic effects of Promethazine that might be long lasting and should be taken into consideration when prescribing this medication, knowing that in many countries Promethazine is available as an over-the-counter (OTC) medication either alone as a tablet or liquid preparation or in combination with paracetamol and codeine phosphate as a syrup.

\section{References}

1. Cantisani C, Ricci S, Grieco T, Paolino G, Faina V, et al. (2013) Topical promethazine side effects: our experience and review of the literature. Biomed Res Int 2013: 151509.

\section{Your next submission with Juniper Publishers} will reach you the below assets

- Quality Editorial service

- Swift Peer Review

- Reprints availability

- E-prints Service

- Manuscript Podcast for convenient understanding

- Global attainment for your research

- Manuscript accessibility in different formats ( Pdf, E-pub, Full Text, Audio)

- Unceasing customer service

Track the below URL for one-step submission https://juniperpublishers.com/online-submission.php 